\title{
Research Article \\ Fuzzy PD Control of Networked Control Systems Based on CMAC Neural Network
}

\author{
Li-lian Huang and Jin Chen \\ College of Information and Communication Engineering, Harbin Engineering University, \\ Harbin, Heilongiang 150001, China \\ Correspondence should be addressed to Li-lian Huang, lilian_huang@163.com
}

Received 16 November 2012; Revised 4 December 2012; Accepted 5 December 2012

Academic Editor: Peng Shi

Copyright (C) 2012 L.-1. Huang and J. Chen. This is an open access article distributed under the Creative Commons Attribution License, which permits unrestricted use, distribution, and reproduction in any medium, provided the original work is properly cited.

The network and plant can be regarded as a controlled time-varying system because of the random induced delay in the networked control systems. The cerebellar model articulation controller (CMAC) neural network and a PD controller are combined to achieve the forward feedback control. The PD controller parameters are adjusted adaptively by fuzzy reasoning mechanism, which can optimize the control effect by reducing the uncertainty caused by the networkinduced delay. Finally, the simulations show that the control method proposed can improve the performance effectively.

\section{Introduction}

Networked control system (NCS) is a distributed and networked real-time feedback control system which combine communication network and control system [1]. Due to the irregularly multiple nodes shared network and data flowing change, information exchange time delay occurred inevitably, which is the network-induced delay [2]. The networkinduced delay will cause system poor control quality and bad performance, even unstable [3-5]. Therefore, the induced delay is one of the most issues in the network control system [6-9].

Based on the influence of the induced delay in the network control system, a cycle time delay network using augmented deterministic discrete time model method is proposed by [10] to control the linear continuous controlled object. In [11] based on the queue management network, the queuing methodology is put forward to turn random time delay into fixed-length time delay. The buffer queue method is designed based on probability predictor delay compensation, according to the problem of random delay in the network 
control system [12]. Zhang et al. [13] studied the stability of network control system with constant delay. Wu et al. [14] propose a delay-dependent sufficient condition by applying the delay partitioning approach for the asymptotic stability with an $H \infty$ error performance for the error system. Wu and Zheng [15] addressed the $L_{2}-L_{\infty}$ dynamic output feedback (DOF) control problem for a class of nonlinear fuzzy ItO stochastic systems with time-varying delay. Yue et al. [16] established the new network control system model considering networkvarying delay, packet loss, and wrong sequence. Peng et al. [17] researched on network control system with interval variable delay and reduced complexity by introducing Jessen inequality. Wu et al. [18] investigated the problems of stability analysis and stabilization for a class of discrete-time Takagi-Sugeno fuzzy systems with time-varying state delay. Wu et al. [19] proposed sufficient conditions to guarantee the exponential stability for the switched neural networks with constant and time-varying delays by using the average dwell time approach together with the piecewise Lyapunov function technique and by combining a novel Lyapunov-Krasovskii functional, which benefits from the delay partitioning method, with the free-weighting matrix technique. In [20] the impact of the network-induced delay is described as a system of continuous-time nonlinear perturbation using nonlinear perturbation theory by assuming no observation noise. Yang et al. introduced a new class of discrete-time networked nonlinear systems with mixed random delays and packet dropouts [21] and discussed the problem of feedback control for networked systems with discrete and distributed delays subject to quantization and packet dropout [22]. Xie et al. [23] discussed the problem of robust $H \infty$ fault-tolerant control for uncertain networked control system with random delays and actuator faults.

In this paper, the PD control with CMAC (cerebellar model articulation controller, CMAC) is proposed. The transmission network and the controlled object are regarded as the time-varying controlled system, in which CMAC neural network implements the forward feedback, while the fuzzy PD composite switching model is applied and adaptive on-line parameters by using fuzzy inference engine are set. The method proposed can reduce the impact of network-induced delay and the uncertainties, so it optimize the control effect and improve the control performance of the system.

The rest of the paper is organized as follows. In Section 2, the problem of time delay in NCS is described. The CMAC neural network-based fuzzy PD controller is put forward in Section 3. Simulation results are shown in Section 4. Finally, a conclusion is provided in Section 5.

\section{The Description of Network Control System with Time Delay}

In network control system, there are three kinds of delay, namely, sensor-controller delay $\tau_{\mathrm{sc}}$, controller computation delay $\tau_{c}$, and controller-actuator delay $\tau_{\mathrm{ca}}$, where the $\tau_{\mathrm{sc}}$ and $\tau_{\mathrm{ca}}$ are caused by the transmission delay generated by the forward channel and feedback channel, and the $\tau_{c}$ is caused by the hardware structure and software code. The controller computation delay $\tau_{c}$ used is to be neglected because it is smaller than $\tau_{\mathrm{sc}}$ and $\tau_{\mathrm{ca}}$. So the total delay of the $k$ th sampling period can be represented as $\tau^{k}=\tau_{\mathrm{sc}}^{k}+\tau_{\mathrm{ca}}^{k}$ [24]. The network control system block diagram is shown in Figure 1.

\section{The Design of CMAC Neural Network-Based Fuzzy PD Controller}

Network control system is time varying because of the network random delay, and the general PID controller will make the control performance worse. But intelligent control has 


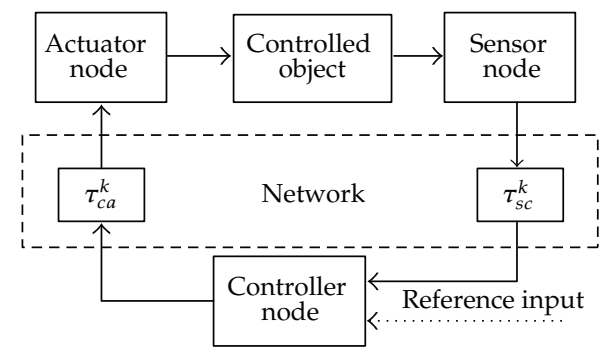

Figure 1: Networked control system.

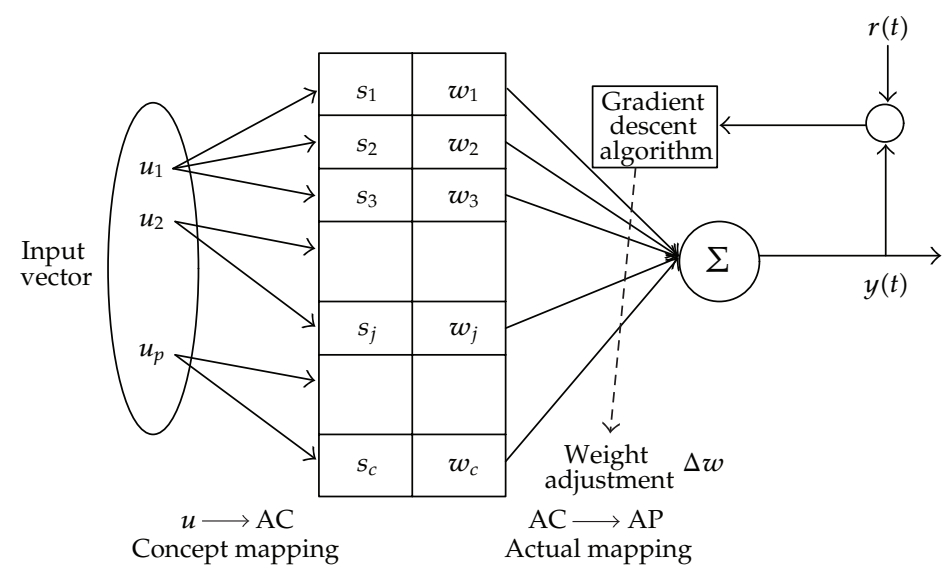

Figure 2: Structure of CMAC network.

a better adaptive ability and is an effective method to improve the system performance [2528], therefore intelligent control is applied to improve the robustness of the system [29-33]. In this paper, CMAC neural network-based fuzzy PD is applied to control the system. We use the PD algorithm instead of the PID, so that the learning of CMAC neural network only depends on the measured and varying values of errors.

\subsection{CMAC Neural Network}

CMAC is a neural network model which can simulate the function of the cerebellar and has the ability to express and inquire complex nonlinear forms adaptively. The network can change the form's information through the learning algorithm and can also store information by category [34]. CMAC consists of input layer, middle layer, and output layer, and its structure is shown in Figure 2.

$\mathbf{u}_{p}=\left[\mathbf{u}_{1 p}, \mathbf{u}_{2 p}, \ldots, \mathbf{u}_{n p}\right]^{T}$ and $\left[u_{p}\right]$ are respectively input space vector and quantization coding, and the input space is mapped to the $c$ memory cells, and $c$ is generalization parameters. The mapping vector is as follows:

$$
\mathbf{R}_{p}=S\left(\left[u_{p}\right]\right)=\left[s_{1}\left(u_{p}\right), s_{2}\left(u_{p}\right), \ldots, s_{c}\left(u_{p}\right)\right]^{T}
$$




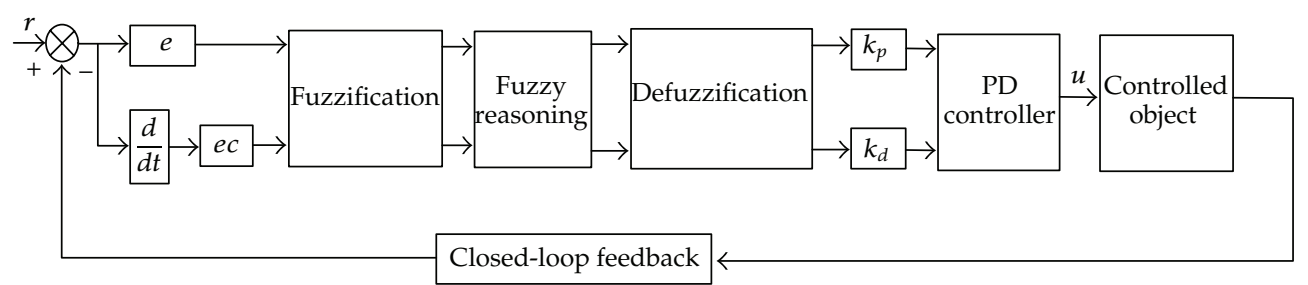

Figure 3: Diagram of fuzzy PD controller.

where $s_{j}\left(\left[u_{p}\right]\right)=1, j=1,2, \ldots, c$. The network's output is the sum of the weights of the $c$ units.

Now only thinking of the single input, the output is

$$
y=\sum_{j=1}^{c} w_{j} s_{j}\left(\left[u_{p}\right]\right)
$$

so

$$
y=\sum_{j=1}^{c} w_{j}
$$

The learning algorithm is as follows.

The $\delta$ learning rule is adapted to adjust the weights, and the norm of weight adjustment is

$$
E=\frac{1}{2 c} e(t)^{2}
$$

where $e(t)=r(t)-y(t)$.

According to the gradient descent, the weights are adjusted as follows:

$$
\begin{gathered}
\Delta w_{j}(k)=-\eta \frac{\partial E}{\partial w}=\eta \frac{r(t)-y(t)}{c} \cdot \frac{\partial y}{\partial w}=\eta \frac{e(t)}{c}, \\
w_{j}(t)=w_{j}(t-1)+\Delta w_{j}(t)+\beta\left(w_{j}(t-1)-w_{j}(t-2)\right),
\end{gathered}
$$

where $w=\left[w_{1}, w_{2}, \ldots, w_{c}\right]^{T}$, and $\beta$ is inertial coefficient.

\subsection{Fuzzy PD Controller}

Fuzzy PD controller takes fuzzy reasoning to adjust the real-time PD parameters. The design of the fuzzy controller includes the fuzzy rules, fuzzy domain, and defuzzification. In this paper, fuzzy algorithm applies the dual-input-output, where signal difference $e$ and difference rate $e c$ are the input, meanwhile, the PD controller proportion coefficient $k_{p}$ and differential coefficient $k_{d}$ are the output, respectively. The structure is shown in Figure 3. 


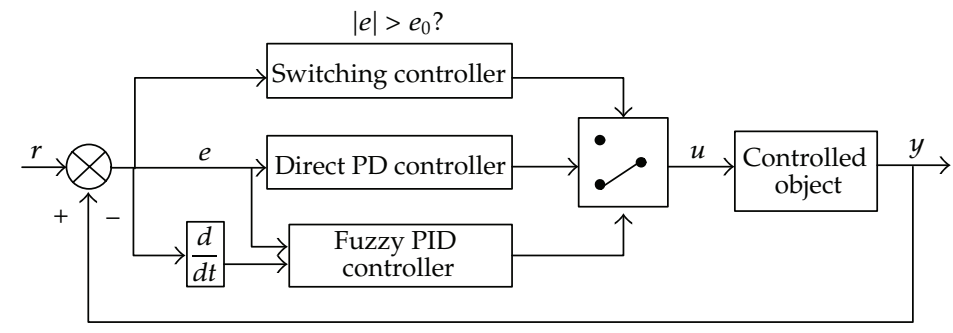

Figure 4: Structure of fuzzy PD switching controller.

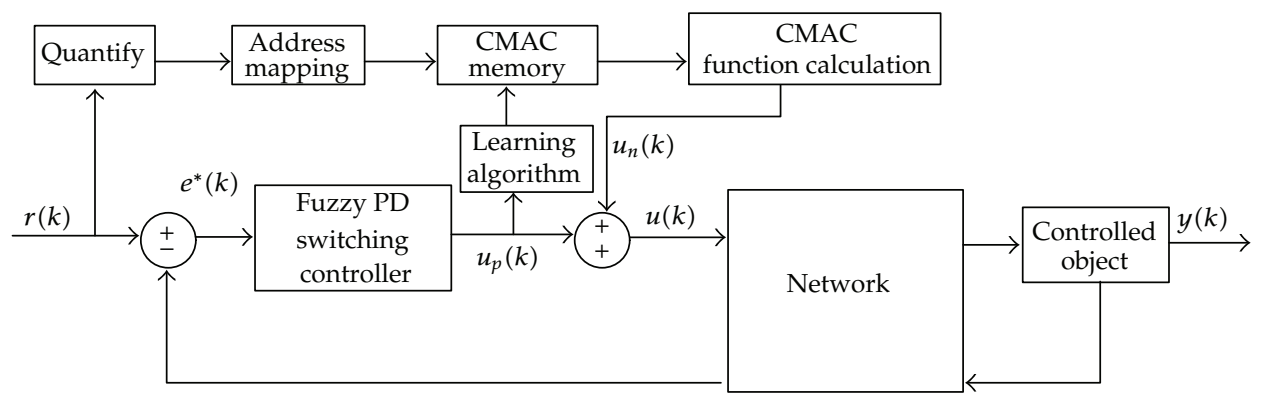

Figure 5: Compound control structure based on CMAC and fuzzy PD.

The fuzzy PD control in a wide range can improve the dynamic response speed, while PD control in a small scale can improve the static control accuracy. So in this paper switching control system between fuzzy PD and PD control is proposed, PD control in the small deviation is applied to obtain higher static control accuracy, and fuzzy PD control in large deviations is applied to obtain faster dynamic response and smaller overshoot. Its structure is shown in Figure 4. The PD control is applied when $|e| \leq e_{0}$ and the fuzzy PD control is applied when $|e|>e_{0}$, where $e_{0}$ is threshold value.

\subsection{Fuzzy PD Composite Controller Based on CMAC Neural Network}

In general, CMAC network is a nonlinear mapping, which is very suitable for online applications because it takes a simple $\delta$ algorithm as learning algorithm. This algorithm has a fast convergence speed and avoids local minimum value problem. The fuzzy PD switching controller is a nonlinear control, which has faster dynamic response, smaller overshoot, and strong robustness. So the CAMC-fuzzy PD controller is designed, which has the advantages of CMAC neural network and fuzzy PD controller. Also it is applied in the network control system with delay. The structure is shown in Figure 5.

The input of CMAC neural network is command signal $\operatorname{rin}(k)$. Using the study algorithm with tutor, calculate the relative neural network output $u_{n}(k)$ of CMAC, compare with the total control input $u(k)$ at the end of each control cycle, then correct weights, and go to the process of learning.

At the beginning of the operating system, fuzzy PD controller plays a major role, while the neural network of CMAC does not work. After a while, the output of CMAC neural network gradually plays a key role by continuous learning the actual output and the expected output values to modify weights. 


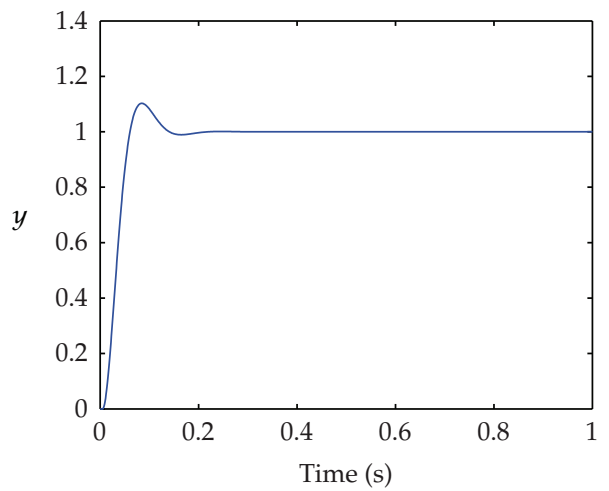

(a) Step response controlled by fuzzy PD

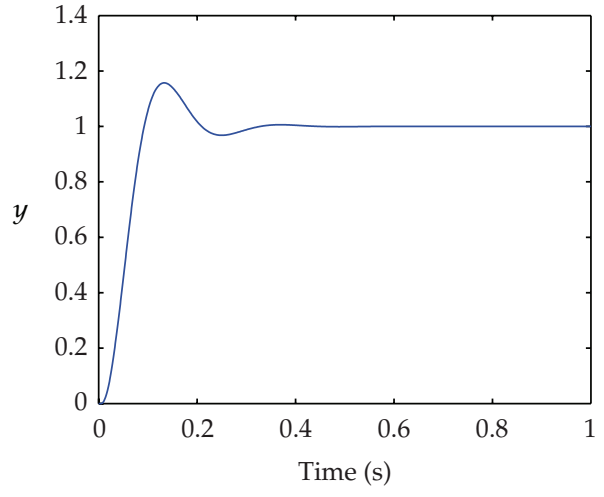

(b) Step response controlled by CMAC-PD

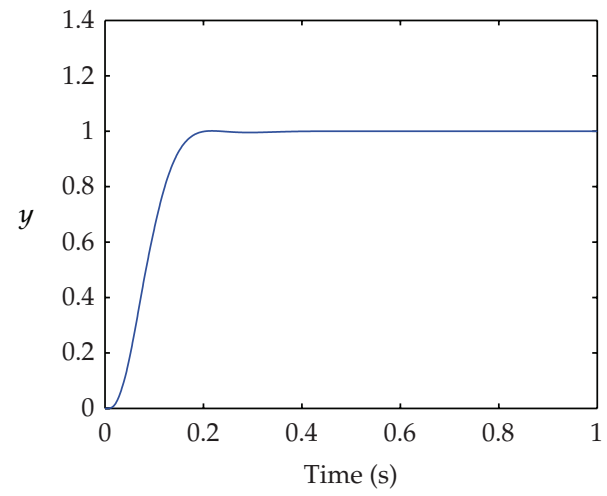

(c) Step response controlled by CMAC-fuzzy PD

Figure 6: Step responses when the mean of time delay is $5 \mathrm{~ms}$.

The control algorithm is

$$
u_{n}(k)=\sum_{i=1}^{c} w_{i} \mathbf{a}_{i}
$$

where $\mathbf{a}_{i}$ is binary choice vector, and $c$ is a generalization parameter.

Consider the following:

$$
u_{p}(k)= \begin{cases}k_{P} * e(k)+k_{d} * e c(k), & |e| \leq e_{0} \\ k_{p}^{\prime} * e(k)+k_{d}^{\prime} * e c(k), & |e|>e_{0}\end{cases}
$$

where $k_{P}$ and $k_{d}$ are parameters preset by PD controller, meanwhile $k_{p}^{\prime}$ and $k_{d}^{\prime}$ are parameters adjusted online by fuzzy PD controller.

The output of system is

$$
u(k)=u_{n}(k)+u_{p}(k),
$$




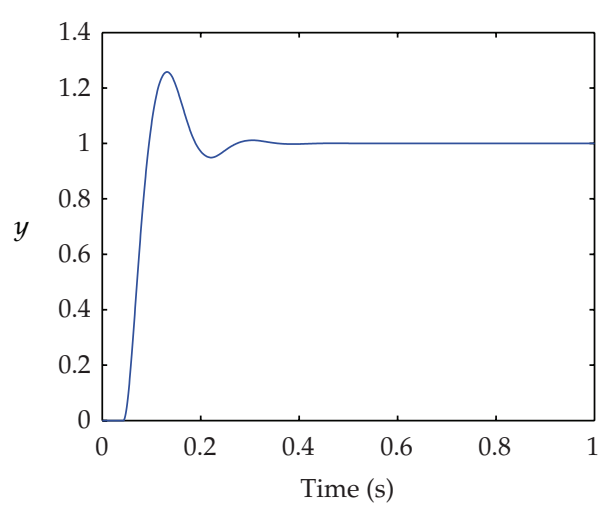

(a) Step response controlled by fuzzy PD

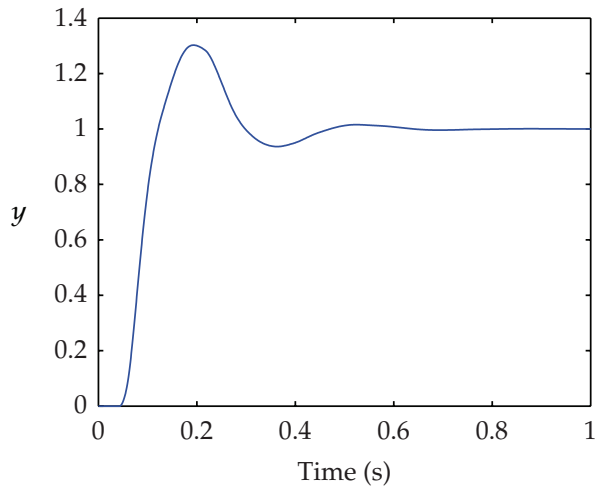

(b) Step response controlled by CMAC-PD

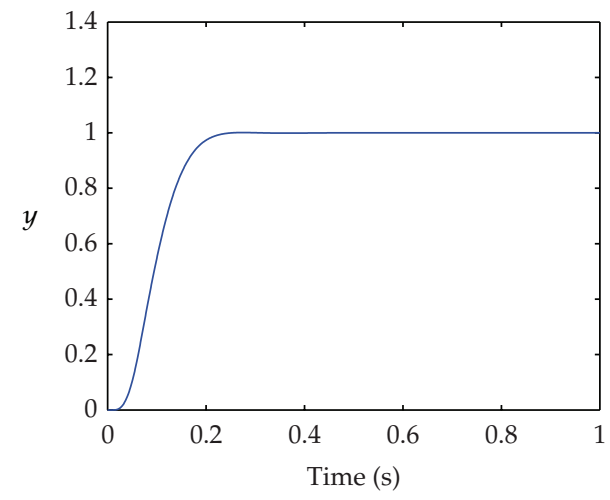

(c) Step response controlled by CMAC-fuzzy PD

Figure 7: Step responses when the mean of time delay is $50 \mathrm{~ms}$.

where $u_{n}(k)$ is the output of CMAC neural network, and $u_{p}(k)$ is the output of the fuzzy PD composites switching controller.

The mapping of CMAC neural network is that the input space is $S$ and the range of $\left[S_{\min }, S_{\max }\right]$ is divided into $N+2 c$ quantization intervals, that is,

$$
\begin{gathered}
v_{1} \cdots v_{c}=S_{\min } \\
v_{j}=v_{j-1}+\Delta v_{j} \quad(j=c+1, \ldots, c+N), \\
v_{N+c+1} \cdots v_{N+2 c}=S_{\max } .
\end{gathered}
$$

The mapping of CMAC is

$$
a_{j}= \begin{cases}1, & \text { if } S_{j} \in\left[v_{j} v_{j+c}\right], j=c+1, \ldots, c+N \\ 0, & \text { other. }\end{cases}
$$


Adjusted index in the learning process is

$$
\begin{gathered}
E=\frac{1}{2 c}\left(u_{n}(k)-u(k)\right)^{2}, \\
\Delta w(k)=-\eta \frac{\partial E}{\partial w}=\eta \frac{u(k)-u_{n}(k)}{c} \cdot a_{i}=\eta \frac{u_{p}(k)}{c} a_{i} \\
w(k)=w(k-1)+\Delta w(k)+\beta(w(k-1)-w(k-2)),
\end{gathered}
$$

where $\eta$ is the rate of network learning, $\eta \in(0,1)$, and $\beta$ is inertial, $\beta \in(0,1)$.

\section{Simulation}

In simulation, the input is the unit step, and the transfer function of controlled object is $(0.0008674 z+0.0008503) /\left(z^{2}-1.94 z+0.9418\right)$. Parameters $N=100, c=5, \eta=0.1, \beta=0.04$, and $k_{p}=0.02, k_{d}=0.06$, and switching threshold $e$ is 0.2 .

The domain of fuzzy algorithm input $e$ and $e c$ is, respectively, $[-6,6]$ and $[-30,30]$. If the actual value of $e$ exceeds the set domain, the value will be limited. The membership function is Gaussian bell-shaped function, which is N, Z, P (negative, zero, positive), respectively; the domain of $k_{p}^{\prime}$ and $k_{d}^{\prime}$ is, respectively, $[0,0.001]$ and $[0,0.1]$, and membership function is also Gaussian bell-shaped function, which is Z, S, M, P (zero, small, medium, large) respectively; Mamdani-type reasoning is adopted and gravity method is defuzzification. Fuzzy lut of $k_{p}^{\prime}$ and $k_{d}^{\prime}$ is, respectively, shown as Tables 1 and 2.

Due to the network delay varies randomly during continuous-time. In simulation, system network delay is generated by Gaussian random signal source, and step responses means for $5 \mathrm{~ms}$ and $50 \mathrm{~ms}$ under Gaussian distribution random delay network. Compared with the traditional CMAC-PD composite control and fuzzy PD control, step response charts are shown in Figures 6 and 7, where sampling time is $1 \mathrm{~ms}$.

From Figure 6(a), we can see that the result is not very good because of the time delay. Under traditional fuzzy PD controller, the step responses of the system show great overshot, long rising time, and large steady state error. In Figure 7(a) especially, when the time delay increases, the fuzzy PD control overshoot of the system is also increased. Otherwise, the result is not ideal under traditional CMAC-PD controller from Figures 6-7(b). Compared with the first two kinds of methods, the CMAC-fuzzy PD controller proposed in this paper is more ideal, especially in the long-delay network. Figures 6-7(c) show that the system has the virtue of stability, precision, fastness, and strong robustness.

\section{Conclusions}

Network control system is the time varying because of the random-induced delay, which results in worse control effects. But the intelligent control has better adaptation and can be used to improve the control performance. This paper regards transmission network and the controlled objects as a time-varying system, combines CMAC neural network algorithm with PD controller to achieve forward feedback control, and adopts the intelligent control strategy. The PD controller introduces fuzzy PD complex switching model. According to the size of the error signal, switching-controller switches between directly PD controller and fuzzy PD 
Table 1: Fuzzy lut of $k_{p}^{\prime}$.

\begin{tabular}{lccc}
\hline$e / e c$ & $\mathrm{~N}$ & $\mathrm{Z}$ & $\mathrm{P}$ \\
\hline $\mathrm{N}$ & $\mathrm{S}$ & $\mathrm{M}$ & $\mathrm{Z}$ \\
$\mathrm{Z}$ & $\mathrm{P}$ & $\mathrm{P}$ & $\mathrm{P}$ \\
$\mathrm{P}$ & $\mathrm{P}$ & $\mathrm{P}$ & $\mathrm{P}$ \\
\hline
\end{tabular}

Table 2: Fuzzy lut of $k_{d}^{\prime}$.

\begin{tabular}{lccc}
\hline$e / e c$ & $\mathrm{~N}$ & $\mathrm{Z}$ & $\mathrm{P}$ \\
\hline $\mathrm{N}$ & $\mathrm{Z}$ & $\mathrm{M}$ & $\mathrm{M}$ \\
$\mathrm{Z}$ & $\mathrm{P}$ & $\mathrm{Z}$ & $\mathrm{P}$ \\
$\mathrm{P}$ & $\mathrm{M}$ & $\mathrm{Z}$ & $\mathrm{S}$ \\
\hline
\end{tabular}

controller, in order to improve the speed of dynamic response of the system and accuracy of steady-state control. Simulation results show that the system has the virtue of stability, precision, fastness, and strong robustness. So that this method can achieve a better effect and can also improve the system's performance effectively.

\section{Acknowledgments}

This work is supported by the Chinese National Science Foundation (no. 61203004), the Natural Science Foundation of Heilongjiang province (no. 42400621-1-12201), and the Fundamental Research Funds for the Central Universities (no. HEUCFT1203).

\section{References}

[1] B. Tang, G. P. Liu, and W. H. Gui, "Improvement of state feedback controller design for networked control systems," IEEE Transactions on Circuits and Systems II, vol. 55, no. 5, pp. 464-468, 2008.

[2] N. Vatanski, J. P. Georges, C. Aubrun, E. Rondeau, and S. L. Jämsä-Jounela, "Networked control with delay measurement and estimation," Control Engineering Practice, vol. 17, no. 2, pp. 231-244, 2009.

[3] I. Hideaki, "Control with limited communication and message losses," Systems and Control Letters, vol. 57, pp. 322-331, 2008.

[4] X. Su, P. Shi, L. Wu et al., "Induced $L_{2}$ filtering of fuzzy stochastic systems withtime-varying delays,: cybernetics," IEEE Transactions on Systems, Man and Cybernetics B. In press.

[5] R. S. Gau, C. H. Lien, and J. G. Hsieh, "Novel stability conditions for interval delayed neural networks with multiple time-varying delays," International Journal of Innovative Computing, Information and Control, vol. 7, no. 1, pp. 433-444, 2011.

[6] M. B. G. Cloosterman, N. van de Wouw, W. P. M. H. Heemels, and H. Nijmeijer, "Stability of networked control systems with uncertain time-varying delays," IEEE Transactions on Automatic Control, vol. 54, no. 7, pp. 1575-1580, 2009.

[7] Y. Shi and B. Yu, "Output feedback stabilization of networked control systems with random delays modeled by Markov chains," IEEE Transactions on Automatic Control, vol. 54, no. 7, pp. 1668-1674, 2009.

[8] X. Su, P. Shi, L. Wu et al., "A novel control design on discrete-time takagi-sugeno fuzzysystems with time-varying delays," IEEE Transactions on Fuzzy Systems. In press.

[9] X. Su, P. Shi, L. Wu et al., "A novel approach to filter design for T-S fuzzy discrete-time systems with time-varying delay," IEEE Transactions on Fuzzy Systems, vol. 20, no. 6, pp. 1114-1129, 2012.

[10] Y. Halevi and A. Ray, "Integrated communication and control systems. Part 1-analysis," Journal of Dynamic Systems, Measurement and Control, Transactions of the ASME, vol. 110, no. 4, pp. 367-373, 1988.

[11] R. Luck and A. Ray, "An observer-based compensator for distributed delays," Automatica, vol. 26, no. 5, pp. 903-908, 1990. 
[12] H. Chan, "Closed-loop control of systems over a communications network with queues," International Journal of Control, vol. 62, no. 3, pp. 493-510, 1995.

[13] W. Zhang, M. S. Branicky, and S. M. Phillips, "Stability of networked control systems," IEEE Control Systems Magazine, vol. 21, no. 1, pp. 84-97, 2001.

[14] L. Wu, X. Su, P. Shi, and J. Qiu, "Model approximation for discrete-time state-delay systems in the TS fuzzy framework," IEEE Transactions on Fuzzy Systems, vol. 19, no. 2, pp. 366-378, 2011.

[15] L. Wu and W. X. Zheng, " $L_{2}-L^{\infty}$ control of nonlinear fuzzy itô stochastic delay systems via dynamic output feedback," IEEE Transactions on Systems, Man, and Cybernetics B, vol. 39, no. 5, pp. 1308-1315, 2009.

[16] D. Yue, Q. L. Han, and C. Peng, "State feedback controller design of networked control systems," IEEE Transactions on Circuits and Systems II, vol. 51, no. 11, pp. 640-644, 2004.

[17] C. Peng, Y. C. Tian, and M. O. Tadé, "State feedback controller design of networked control systems with interval time-varying delay and nonlinearity," International Journal of Robust and Nonlinear Control, vol. 18, no. 12, pp. 1285-1301, 2008.

[18] L. Wu, X. Su, P. Shi, and J. Qiu, "A new approach to stability analysis and stabilization of discrete-time T-S fuzzy time-varying delay systems," IEEE Transactions on Systems, Man, and Cybernetics B, vol. 41, no. 1, pp. 273-286, 2011.

[19] L. Wu, Z. Feng, and W. X. Zheng, "Exponential stability analysis for delayed neural networks with switching parameters: average dwell time approach," IEEE Transactions on Neural Networks, vol. 21, no. 9, pp. 1396-1407, 2010.

[20] G. C. Walsh, O. Beldiman, and L. G. Bushnell, “Asymptotic behavior of nonlinear networked control systems," IEEE Transactions on Automatic Control, vol. 46, no. 7, pp. 1093-1097, 2001.

[21] R. N. Yang, P. Shi, and G. P. Liu, "Filtering for discrete-time networked nonlinear systems with mixed random delays and packet dropouts," IEEE Transactions on Automatic Control, vol. 56, no. 11, pp. 26552660, 2011.

[22] R. N. Yang, P. Shi, and G. P. Liu, "Network-based feedback control for systems with mixed delays based on quantization and dropout compensation," Automatic, vol. 47, no. 12, pp. 2805-2809, 2011.

[23] D. Xie, D. Zhang, and Z. Wang, "Robust $H^{\infty}$ faulttolerant control for uncertain networked control system with two additive random delays," International Journal of Innovative Computing, Information and Control, vol. 7, no. 1, pp. 315-326, 2011.

[24] L. Fu and G. Z. Dai, "A survey of networked control systems," Computer Engineering and Applications, vol. 41, no. 25, pp. 221-225, 2005.

[25] L. Wu and D. W. C. Ho, "Fuzzy filter design for Itô stochastic systems with application to sensor fault detection," IEEE Transactions on Fuzzy Systems, vol. 17, no. 1, pp. 233-242, 2009.

[26] F. Q. Liu and X. P. Xue, "Constructing kernels by fuzzy rules for support vector regressions," International Journal of Innovative Computing, Information and Control, vol. 8, no. 7, pp. 4811-4822, 2012.

[27] K. Z. Ghafoor, K. A. Bakar, S. Salleh et al., "Fuzzy logic-assisted geographical routing over Vehicular AD HOC Networks," International Journal of Innovative Computing, Information and Control, vol. 8, no. 7, pp. 5095-5120, 2012.

[28] J. Botzheim and F. Példesi, "Parametric approximation of fuzzy exponent for computationally intensive problems," International Journal of Innovative Computing, Information and Control, vol. 8, no. 8, pp. 5725-5744, 2012.

[29] S. Lee, S. H. Lee, K. C. Lee, M. H. Lee, and F. Harashima, “Intelligent performance management of networks for advanced manufacturing systems," IEEE Transactions on Industrial Electronics, vol. 48, no. 4, pp. 731-741, 2001.

[30] S. E. Shafiei and M. R. Soltanpour, "Neural network sliding-mode-PID controller design for electrically driven robot manipulators," International Journal of Innovative Computing, Information and Control, vol. 7, no. 2, pp. 511-524, 2011.

[31] T. Chaiyatham and I. Ngamroo, "A bee colony optimization based-fuzzy logic-pid control design of electrolyzer for microgrid stabilization," International Journal of Innovative Computing, Information and Control, vol. 8, no. 9, pp. 6049-6066, 2012.

[32] X. Su, L. Wu, P. Shi et al., " $H^{\infty}$ model reduction of takagi-sugeno fuzzy stochastic systems," IEEE Transactions on Systems, Man, and Cybernetics B, vol. 42, no. 6, pp. 1574-1585, 2012.

[33] H. M. Feng and H. C. Chou, "Evolutionary fuzzy stock prediction system design and its application to the Taiwan stock index," International Journal of Innovative Computing, Information and Control, vol. 8, no. 9, pp. 6173-6190, 2012.

[34] C. Y. Leng and J. P. Yu, "The application of CMAC neural network to DTC control system," Machine Building and Automation, no. 12, pp. 78-83, 2004. 


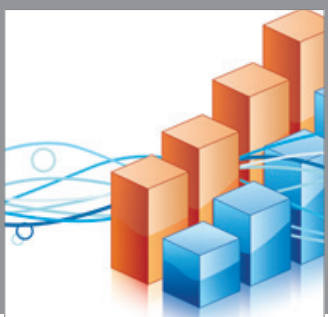

Advances in

Operations Research

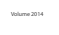

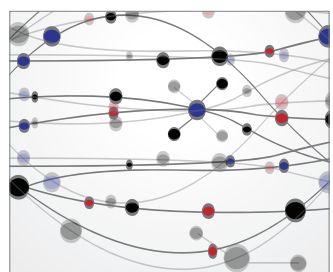

\section{The Scientific} World Journal
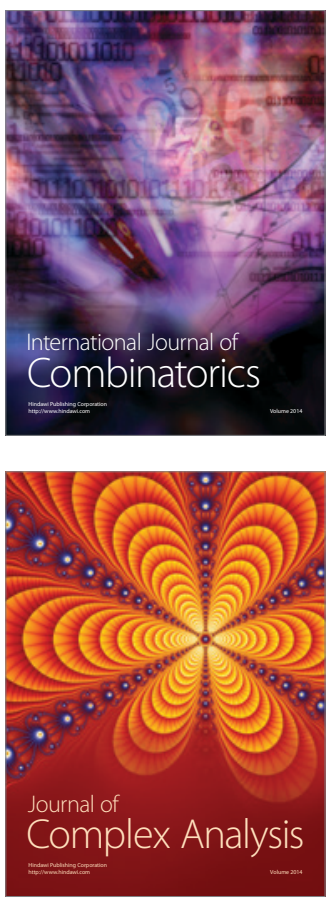

International Journal of

Mathematics and

Mathematical

Sciences
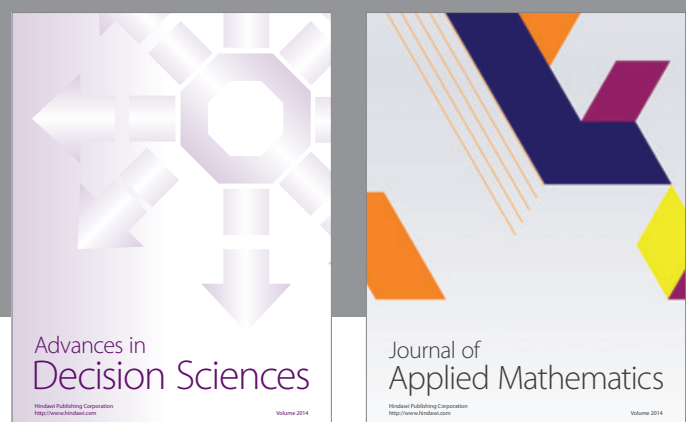

Journal of

Applied Mathematics
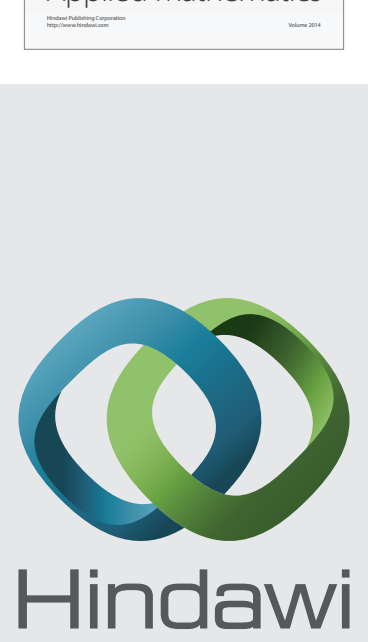

Submit your manuscripts at http://www.hindawi.com
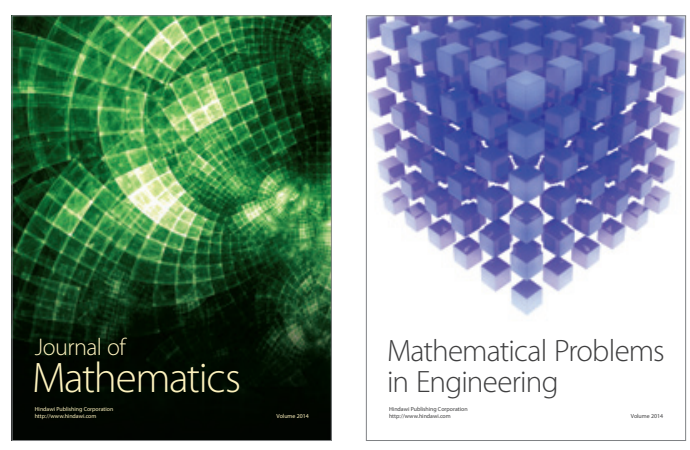

Mathematical Problems in Engineering
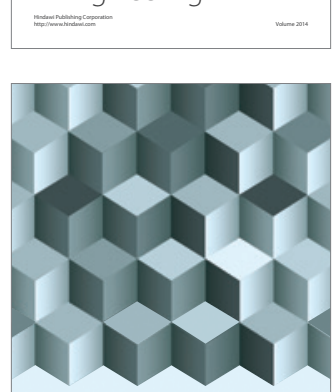

Journal of

Function Spaces
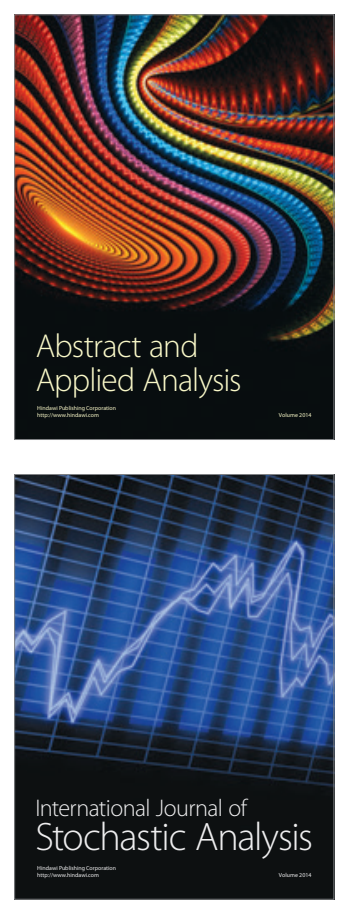

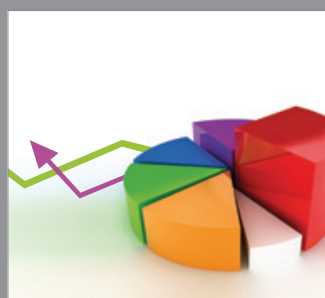

ournal of

Probability and Statistics

Promensencen
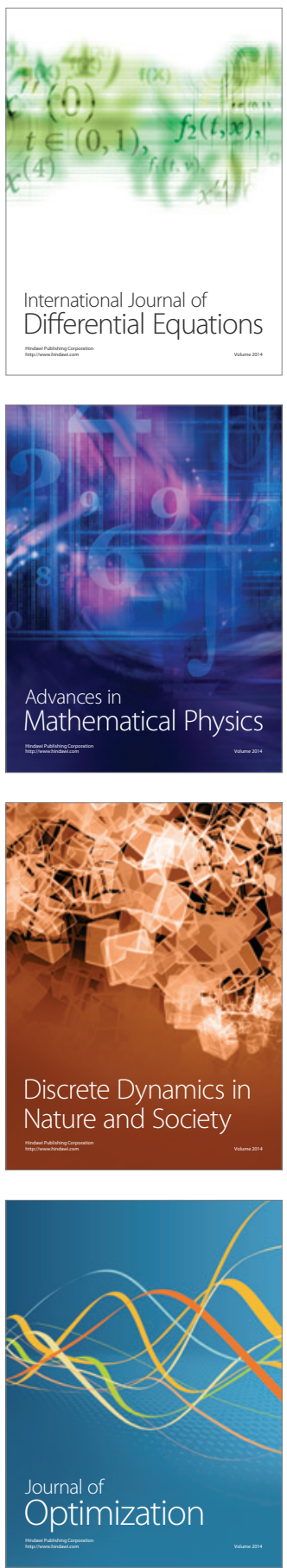